\title{
ALGUNAS CUESTIONES SOBRE EL CONCEPTO DE MEJORA
}

\author{
CAMINO CAÑÓN LOYES \\ Universidad Pontificia Comillas, Madrid
}

\begin{abstract}
RESUMEN: En los años ochenta emergió la cuestión de la licitud moral de la mejora por relación a la terapia. Para presentar la problemática actual sobre el tema se ofrece el constructo denominado Práctica de Intervención del Cuerpo (PIC) caracterizado por cinco parámetros: M o la materia de la transformación, CT o la tecnociencia disponible, A o las concepciones vigentes de lo natural y lo artificial, $\mathrm{N}$ o las visiones de la naturaleza humana culturalmente compartidas y $\mathrm{V}$ o las valoraciones éticas a las que se apela para legitimar la transformación. Se apunta el nivel ontológico como necesario para comprender y debatir las diferencias existentes en criterio moral. El concepto de naturaleza humana como referente normativo está en crisis, pero su ausencia deja un vacío que hace urgente una deliberación para llegar a una instancia normativa común.
\end{abstract}

PALABRAS CLAVE: terapia, mejora, naturaleza humana, transhumanismo.

\section{Immaterialism and Realism $\boldsymbol{n}$ Berkeley}

ABSTRACT: In the eighties, the question of the moral legitimacy of enhancement related to therapy emerged. In order to approach the issue at the present, the author gives the concept: Bodily Intervention Practices (BIP), characterised by five parameters: $\mathrm{M}$ or the material involved in the transformation, TC or the available technoscience, $\mathrm{A}$ or the current conceptions regarding the natural and the artificial, $\mathrm{N}$ or the concept of human nature culturally shared and $\mathrm{E}$ or the ethical evaluations appealed to justify the transformation. The ontological level is indicated as necessary in order to understand the present debate the existing differences in moral criteria. The concept of human nature as a normative reference is in crisis and its absence leaves a vacuum which makes the need for deliberation with the aim of reaching common normative criteria urgent.

KEY WORDS: therapy, enhancement, human nature, transhumanism.

\section{El AYER}

En mayo de 1989, el doctor Anderson, investigador en el National Institute of Health de Estados Unidos, en Bethesda, obtuvo el primer protocolo de curación del cáncer por medio de la tecnología de transferencia de genes y un año después tuvo lugar el reemplazamiento de un ADA, un gen defectuoso en una niña de 4 años. La investigación que le condujo a estos logros fue acompañada por serias reflexiones acerca de las implicaciones éticas que esta nueva posibilidad tecnológica estaba abriendo. Su inquietud entonces la expresaba con una analogía, recordando que el impacto ocasionado por la bomba atómica en Japón, no había sido tomado en cuenta por los investigadores que crearon esa arma letal. Un artículo suyo del año 1985, y particularmente otro del año $1989^{1}$, planteaban la cuestión de cómo discernir la licitud ética de mejora como un tema de importancia capital.

1 W. F. Anderson (1985): «Human gene therapy: Scientífic and ethical considerations», The Journal of Medicine and Philosophy 10, pp. 275-291; W. F. Anderson (1989): «Human gene therapy: Why to draw a moral line?», The Journal of Medicine and Philosophy 14, pp. 681-693. 
El modo de abordarlo el doctor Anderson era tratarlo en relación con la terapia. Expresaba así, junto a su convicción de que la nueva tecnología debía estar al servicio de los fines de la medicina, es decir al servicio de la terapia, sus temores de que la extrapolación a situaciones de mejora, condujera a la humanidad por derroteros no deseables y en algunos casos claramente rechazables.

Mi estudio de la cuestión en aquel momento fue una aproximación a partir de la teoría de definiciones ${ }^{2}$. Anderson plantea dos pasos: Si se debe trazar una línea moral, y en caso afirmativo por dónde y cómo debería ser trazada. Y se confronta con dos niveles: la discusión sobre las fronteras con el conocimiento disponible y, en segundo lugar, la relación entre el conocimiento disponible y las restricciones morales. Mis reflexiones conclusivas llevaban a afirmar que la tecnología de transferencia de genes abrió posibilidades nuevas para tratar a los seres humanos, lo cual requiere nuevos marcos, nuevos nombres y nuevas maneras de pensar lo que es bueno para los seres humanos. Esto quedó concretado en cuatro conclusiones, que sintetizo:

1) Es necesario diferenciar entre dos tipos de líneas morales: la que se traza para evitar el daño a la especie humana y otro tipo de línea moral, que denomino «línea moral prudencial»

2) La primera debe ser trazada (primum non nocere), pero el conocimiento empírico disponible es insuficiente para determinar dónde debe ser trazada.

3) La línea moral prudencial, aunque cambiable no es arbitraria, y los actuales significados de terapia y de mejora deben ser revisados a la luz de los conocimientos disponibles y del desarrollo de la conciencia moral de la sociedad, pues de otra manera, se corre el peligro de caer en un nominalismo por no corresponder a los problemas reales.

4) La conclusión del argumento: «se debe trazar una línea moral entre terapia y mejora», o se considera trivial o encierra una petición de principio. Pues esa conclusión se obtiene bajo el supuesto de reservar la dimensión prescriptiva para algunos de los rasgos del definiens de terapia, mientras que se asigna una mera dimensión descriptiva para todos los rasgos de la mejora.

Estas conclusiones formuladas en el año 1990 suenan hoy insignificantes; sin embargo, la cuestión, lejos de haberse resuelto, se ha problematizado en esas direcciones. ¿Por qué la mejora no puede incluir rasgos de prescriptividad? Si se le reconocieran, pasaría a ser automáticamente terapia y estaría al otro lado de la línea moral. Pero, ¿es este paradigma terapia/mejora el que orientará las decisiones del próximo futuro?

\footnotetext{
2 Tuve la oportunidad de participar en un seminario de trabajo en su laboratorio (Noviembre 1989 y mayo 1990), organizado por el entonces Seminario Internacional de Bioética de la FIUC y presididas por él. En la segunda sesión presenté una ponencia sobre la cuestión de las definiciones de terapia y de mejora utilizando el modelo de definición "gradiente» como alternativo al modelo "componencial» habitual en el que el definiens se compone de condiciones necesarias tales que su conjunción es una condición suficiente. En el modelo «gradiente» empleo el conocido como modelo «prototipo» en el que intervienen rasgos jerarquizados: imprescindibles, esperados, posibles, inesperados y excluidos. En el modelo "gradiente» estas diferencias son expresadas mediante los coeficientes de las componentes de un vector en el que algunos coeficientes que toman valor uno en el caso de la terapia, toman valor cero en el caso de la mejora y recíprocamente. Pero hay otros que su valor depende significativamente de al menos cuatro factores: conocimiento disponible, comprensión social de lo que está en juego, valoración de las consecuencias que se siguen, y finalmente, pero no por ser menos importante, el apoyo de los principios implicados en la aceptación o rechazo.
} 
2. EL HOY

En el tiempo presente estamos asistiendo a una proliferación de aproximaciones a lo que denominaré práctica de intervención del cuerpo (PIC). En un tiempo de crisis del viejo paradigma, hay muchos candidatos para ocupar el nuevo lugar. Aún está por ver si lo que va a emerger tendrá elementos sustantivos de continuidad con lo anterior o se dará una ruptura, al modo como se establece en la descripción teórica de Thomas Khun. Para analizar los elementos que están en juego voy a adecuar un constructo tomado de la filosofía de la matemática, que espero sea útil para la finalidad que buscamos aquí ${ }^{3}$, que no es otra que la de aportar algunos elementos para esclarecer las reflexiones y deliberaciones en torno a la mejora humana. Caracterizo la PIC por los siguientes cinco rasgos: M o la materia de la transformación; sea corregir la miopía, o implementar una vista de águila, incrementar las capacidades de un atleta o de un matemático, etc. CT o los conocimientos científicos y las técnicas correspondientes, disponibles en el tiempo en el que se planea y se realiza la intervención. A o las concepciones vigentes acerca de lo natural y lo artificial. $\mathbf{N}$ o las concepciones de la naturaleza humana culturalmente compartidas por los profesionales y quienes son intervenidos. $\mathbf{V}$ o las valoraciones éticas a las que se apela para legitimar la transformación.

¿Por qué proponemos este instrumento de análisis? Porque entendemos que tanto en el inicio de la problematización de la mejora como en las décadas que nos separan de entonces, ha habido cambios en algunas de las componentes mencionadas cuya conjugación pueden ayudarnos a comprender mejor donde están las cuestiones que necesitan ser clarificadas y dónde están, también, los puntos que requieren toma de postura ontológica, epistemológica o ética. De qué modo los cambios en alguna de las componentes mencionadas pueden influir decisivamente en los cambios de otras componentes es una cuestión relevante para una mejor comprensión de lo que está en juego en el terreno de las decisiones que acompañan a las PIC. Comprensión que posibilitará un acercamiento para discernir acerca de las posibles rupturas epistemológicas que se están efectuando en alguna de ellas y, también, para distinguir lo que puede ser una simple moda de un cambio irreversible.

El Dr. Anderson, en sus escritos de los años ochenta, observaba que existía «precariedad de criterio moral común». Podríamos decir que en los años que nos separan de entonces, la precariedad puede ser descrita mejor como «disparidad». Una disparidad que no se reduce a posibilidades diversas dentro de un tronco común. La diversificación actual es patente en la amplísima literatura que hay sobre el tema y, podríamos conjeturar, que de los cinco elementos que caracterizan las PIC: $<\mathrm{M}, \mathrm{CT}, \mathrm{A}, \mathrm{N}, \mathrm{V}>$, el segundo ha sido determinante para las variaciones del primero, y concomitante con las variaciones de los otros que participan, a mi juicio, de lo que podríamos llamar una causa común: la crisis de la metafísica que dejó sin asideros los discursos que constituían la base común para asentar el concepto de naturaleza humana como concepto normativo. Veamos pues, de manera diferenciada estos apartados.

3 Me refiero al constructo teórico matemático acuñado por PH. KITcHER (1983): The nature of mathematical knowledge. New York: Oxford University Press. Puede verse también una aplicación del mismo en la parte quinta de mi libro: C. CAÑón (1993): La matemática, creación y descubrimiento. Madrid: Universidad Pontificia Comillas, pp. 359-382. 


\subsection{M o la materia de la transformación}

Aunque este es el primer aspecto a tener en cuenta, en el contexto de transformación que estamos viviendo no es una cuestión obvia. En buena medida, la indefinición que existe en este momento respecto de lo que es lícito transformar pone de relieve, por una parte, que «no todo vale» cuando se trata del cuerpo humano y, por otra, que el debate es complejo y que la materia de la transformación lejos de ser el punto de partida, se ha convertido en punto de llegada, como veremos al analizar las otras componentes.

\subsection{Los avances de las ciencias y de las tecnologías}

En este comienzo del siglo xxI, estamos inmersos en un avance sólo concebible por la ciencia ficción en las décadas precedentes. La ideación de Orwell de El Gran Hermano en su novela 1984 (1949), o El mundo feliz de Huxley (1932), ya han dejado de sorprendernos y hasta nos empiezan a resultar familiares; las creaciones de la imaginación que sirven de inspiración para los avances científicos y tecnológicos encuentran nuevas formas que se suceden unas a otras en períodos de tiempo muy cortos gracias a los avances extraordinarios de las tecnociencias BIO, NANO, INFO, NEURO, y de los proyectos múltiples de las CT o tecnologías convergentes ${ }^{4}$.

En estos años hay muchas fuerzas convergentes que se están uniendo para crear una corriente social nueva y muy poderosa. En el centro está una revolución tecnológica en cuyo horizonte está la transformación de nuestras instituciones, de nuestro mundo y de nosotros mismos. Los científicos han comenzado a reorganizar la vida; la biosfera se ha quedado pequeña y estamos ya inmersos en lo que se conoce como Infosfera ${ }^{5}$. Se trabaja con la pretensión de obtener vida en el laboratorio y de identificar los procesos cerebrales que están en la base de las funciones correspondientes a la dimensión espiritual humana. Hay frutos de este matrimonio entre genes y computadores que nos van a sorprender profundamente en las próximas décadas. Un ejemplo en el campo de la bioinformación es la creación un nuevo género de bancos de datos biológicos que permiten acceder a información codificada por millones de años el proceso evolutivo. Son instrumentos que ofrecen oportunidades para remodelar la vida en la tierra y abren nuevas vías a la pretensión de controlar el proceso evolutivo.

Las nuevas generaciones contemplarán nuestro tiempo con una distancia que quizás nos parezca hoy inconcebible. El siglo de la biotecnología, como se ha llamado al siglo xxi, avanza cambios que afectarán profundamente a la consciencia individual y colectiva y al futuro de la civilización. En el caso de las transformaciones en el cuerpo humano nos encontramos en un terreno de particular trascendencia, pues se trata de comprender qué significa en este contexto la dignidad humana, qué lugar se reconoce al ser humano en el universo, con qué lenguaje se abordan las cuestiones que hasta ahora se reconocen como terapia y mejora.

Y junto a todo ello, hay una realidad que desde la ciencia y la tecnología no puede contemplarse, pero que nos recuerda constantemente y tozudamente el rozamiento de

4 Puede encontrarse información abundante sobre este punto en N. URSÚA (2013): «Advantages and risks of naturalización», en J. I. GalParsoro y A. Cordero (eds.) (2013): Reflections on Naturalism. Rotterdam: Sense Publishers, pp. 130-149

5 Véase: L. FloRIDI, (2007) «A look into the future impact on ICT on our lives» en The Information Society 23,1, pp. 3-4. Pueden verse los artículos sobre esta temática de M. Ortega de Mues, A. Sánchez Orantos, J. LEACH y J. PEREÑa, en el número monográfíco sobre Filosofía de la web de Diálogo Filosófico, n87 (2013) pp. 412-467. 
la contingencia, de la enfermedad, de la muerte y del mismo deterioro que los avances tecnocientíficos han causado y siguen causando en la naturaleza. Hay también otros elementos de contingencia que corresponden a la cultura y que presentan otro tipo de rozamiento para los avances que las ciencias puedan pretender llevar a cabo. Son las cuestiones a las que se refieren los otros tres elementos de las PIC: A, N y V. Veámoslo.

\subsection{A o las concepciones acerca de lo natural y lo artificial}

En nuestro tiempo, la dicotomía entre lo natural y lo artificial es vista por algunos como una discontinuidad que pertenece al pasado 6 . Ya no podemos imaginarnos modos de vivir humanamente sin pensar en la técnica: la higiene, las relaciones, el vestido, el cobijo, el cultivo de la tierra, todo está hoy mediado por la técnica fecundada por la ciencia, es decir, por la tecnología o, si se prefiere, por la tecnociencia. El viejo mecanicismo ha encontrado en la tecnología un nuevo eslabón de la evolución humana. Marvin Misky dice que: "Man is a meat computer», y los transhumanistas sueñan con que la fusión del hombre con la máquina dé el paso a una inmortalidad terrena.

Pero no es infrecuente que, en la cultura ambiente, lo natural sea simplemente considerado como aquello que no ha sido transformado sustancialmente por la acción humana, mientras que lo artificial sería lo que ha sufrido alguna transformación debido a esa intervención de los humanos. Así, escribir una carta en papel puede ser considerado como natural, mientras que escribir un e-mail o un mensaje de móvil aparezca como artificial. Por otra parte, no es sólo esta cuestión de demarcación la que a menudo está oscura, sino que también se da la coexistencia de actitudes diversas ante la relación entre lo natural y lo artificial; ejemplificaré esto último con dos autores clásicos que poseen visiones extremas.

Pensemos, por ejemplo, en Ortega y Gasset y su visión optimista. Considera que el homo sapiens es por derecho propio también homo faber. La técnica deviene así constitutiva de la naturaleza humana, es el gran aparato ortopédico que permite a los seres humanos vivir en una realidad demasiado dura para ellos. Viene a ser uno de los modos del avance evolutivo que invierte el proceso de adaptación del ser humano al entorno, para adaptar éste al ser humano, y en esta inversión ¿tendría sentido deslindar lo artificial de lo natural? ${ }^{7}$.

La visión de la tecnología como antagonista de la naturaleza encuentra su expresión clásica en la obra de Jacques Ellul ${ }^{8}$. Este autor sostiene que la técnica primitiva se aplicaba aspectos limitados y concretos de la actividad, mientras la tecnología moderna encierra al hombre en un mundo artificial del que no puede traspasar el muro a encontrar su hábitat natural, su lugar de reposo. Pero la ciencia y la tecnología tenderá siempre, en opinión de este autor, a garantizar la ilusión de la libertad de modo que, con estímulos inducidos, mantendrá a los humanos en un estado falso de felicidad, en la búsqueda

6 Bruce Mazlish menciona cuatro dicotomías que caracterizan el pensamiento occidental a lo largo de la historia: la primera separaba los cielos de la tierra y de sus fenómenos físicos, la segunda establecía que el ser humano tenía un linaje independiente del resto de la naturaleza, estaba hecho directamente por Dios a su imagen y semejanza. La tercera afirma que el ser humano tiene una libertad que, a diferencia de los animales, le libera de actuar en función de sus instintos y la cuarta es la que se da entre lo natural y lo artificial de la que venimos hablando. (Ver J. Bustamante (2011): «La evolución del concepto de naturaleza en la filosofía de la tecnología» en C. Alonso Bedate (ed.) (2011): Lo natural, lo artificial y la cultura. Madrid: Universidad Pontificia Comillas, pp. 17ss).

7 Ortega habla de la «técnica» pero bien podríamos validar lo que dice para la «tecnología».

8 Véase por ejemplo su obra clásica: J. Ellul (1960): El siglo Xx y la técnica: análisis de los conquistas y peligros de la técnica en nuestro tiempo. Barcelona: Labor. Traducción de Adolfo Maíllo. 
incansable de su realización, prometiendo un sentido que se aleja cada vez más del cotidiano vivir. Lo artificial ha colonizado la naturaleza y se hace centro de atracción de los deseos humanos.

Estas visiones, pesimista la última, optimista la anterior, llevan a plantearnos la cuestión de si existe realmente oposición entre lo artificial y lo natural. El propio Bacon, símbolo de la dominación de la naturaleza por los seres humanos, — del «progreso»—, al descubrir que la ciencia moderna podía fecundar a la vieja técnica, de modo que el fruto fuera un nuevo poder inconcebible hasta entonces, nos dejó un adagio lleno de sabiduría: «sólo obedeciéndola se doblega a la naturaleza»(«natura non nisi parendo vincitur $\left.»^{9}\right)$. Pero, esta etapa de la historia reciente está llena de ejemplos de cómo el desarrollo tecnológico ha ignorado la sabiduría contenida en la frase del Barón de Verulam. La ciencia se ha hecho a menudo con la convicción de que sus teorías son sólo construcciones, que la naturaleza no tiene «nada que decir», la tecnología «no se ha doblegado ante la naturaleza» y estamos recogiendo las consecuencias de numerosos desastres, hasta el punto de que Ulrich Beck ha hablado de "modernidad reflexiva»" para indicar que los desarrollos tecnológicos deben tomar en consideración los efectos que producen en la naturaleza, y que aunque no fueron directamente buscados, de hecho la alteran gravemente. Lo cual no hace sino confirmar el dicho de Bacon, pues la naturaleza parece no doblegarse cuando no se la ha obedecido previamente; se manifiesta vulnerable y los efectos nocivos se vuelven contra la vida, y como consecuencia, contra los seres humanos.

$\mathrm{Si}$, con estos considerandos, pensamos en la naturaleza humana, nos encontramos con que somos llevados casi de la mano a preguntarnos ¿cómo se relacionan lo natural y lo artificial en los humanos?, ¿cuál es la concepción de naturaleza humana que subyace a la respuesta anterior? ¿Son las mejoras que se proponen modos de doblegar esa naturaleza siguiendo las pautas que ella misma impone? ¿Cómo saber a qué hemos de obedecer?

\subsection{Sobre la naturaleza humana}

Cualquier mejora que se pretenda, ha de pasar por alguna intervención en el cuerpo humano. El punto de partida venía siendo la diferenciación entre terapia y mejora, justificada aquella —en un amplio sector de la ética médica y en las tradiciones religiosas cristianas- por la dimensión prescriptiva inherente al proceso de restauración del orden intrínseco a la propia naturaleza. Es decir, las valoraciones morales más comunes en la ética médica, compartían un núcleo interpretativo respecto de la naturaleza humana. Esta era algo más que la naturaleza animal, y no era reducible a ella.

Cabe preguntarse con Hume, «si es en la Naturaleza donde debemos buscar estos principios o si hay que suponerles algún otro origen», y también a responder con él: "A esto replicaría que nuestra respuesta dependerá de la definición de la palabra Naturaleza, pues, no existe término más ambiguo y equívoco ${ }^{11}$. Hoy, el diccionario de la RAE ofrece un conjunto de acepciones del término que van desde una referencia a lo dado: «Conjunto de las cosas y de las fuerzas que componen el universo y que no han sido hechas por el ser

9 F. BAcon (1984): Novum Organum, libro I, aforismo 129. Barcelona: Editorial ORBIS, p. 81.

10 U. Beck (2002): La sociedad del riesgo. Barcelona: Paidós. Barcelona. (Original alemán, 1986).

11 D. Hume (1740): Tratado sobre Naturaleza Humana, 7/11. 
humano», hasta la apelación a un "principio universal que gobierna y dispone todas las cosas» ${ }^{12}$.

Pero la apelación al término «naturaleza» requiere decir algo acerca del concepto nombrado por ese término. En Grecia, ya en el siglo séptimo a. C., se acuña el concepto de physis, que posibilitará el concepto ontológico «naturaleza», el cual tiene un referente ostensivo: lo dado. El lenguaje que ontologiza la physis, como acabamos de mencionar, llega hasta hoy: sustancia, potencia,... de modo que la naturaleza deviene un principio de determinación de lo que la cosa es. Además de principio es sustancia, aquello inmóvil subyacente en todos los seres. La naturaleza lleva además el principio inteligible de las cosas, principio de racionalidad. Supone la existencia de unas leyes que la configuran dotándole de una orientación, de un telos. La razón ordenadora del cosmos integra el mundo humano, de ahí que la ley natural es la participación del hombre en la ley eterna aplicada a un sector del mundo como es el humano ${ }^{13}$.

Así, en la comprensión premoderna, la naturaleza y la naturaleza humana en particular, eran entendidas en referencia a sus causas finales y formales. La metafísica proporcionaba los elementos para dar cuenta de un concepto que sustentado en la realidad natural, el cuerpo, iba mucho más allá del dato empírico. Veía orden y finalidad en ella, la dotaba de dimensión invariable y normativa. La existencia de naturaleza humana ha sido objeto de gran debate histórico a lo largo de la modernidad y los autores de la posmodernidad, la rechazan directamente como consecuencia de su rechazo de la metafísica.

Al entrar en crisis la metafísica propia de este modelo físico-ontológico, emergen otros modelos menos firmes, como el modelo empirista de David Hume, en su Tratado de la naturaleza humana. Para este autor, la naturaleza humana ya no es normativa, la naturaleza se describe y por consiguiente, no puede apelarse a ella como instancia prescriptiva. De ahí que denuncie como falacia naturalista la inferencia de un «debe», propio del lenguaje normativo, a partir de un «es», propio del lenguaje descriptivo, que es el propio de la naturaleza, también de la naturaleza humana. De este modo, el término «naturaleza» corresponde, en esta visión, a un concepto objetivable por las ciencias empíricas. Una posición bien conocida por los naturalismos de hoy.

El concepto de naturaleza elaborado por Hume cobra nueva fuerza en el empirismo postkantiano de Mill, y recibe un fuerte impulso con el evolucionismo darwinista, hasta llegar a impregnar un amplio sector de la cultura actual en el que las diversas formas de naturalismo permean en sus formas fuertes —ontológicas—, o débiles —epistemológicas- una buena parte de los debates actuales, tanto en bioética como en las cuestiones sobre ciencia y religión ${ }^{14}$.

En el siglo XIX emerge, como hilo conductor para comprender la naturaleza humana, otro punto de referencia: el cuerpo. Es el caso de Nietzsche y, con posterioridad, también de la fenomenología, Zubiri y Laín Entralgo. Emergen así dos respuestas posibles a la pregunta: cuando hablamos del cuerpo, ¿a qué nos referimos? Porque podemos referirnos al «cuerpo viviente» o al «cuerpo objetivo». Si al primero, nos movemos en el ámbito

12 Pannikar señala hasta ocho acepciones: Nacimiento, generación de lo viviente. Principio engendrante. Principio intrínseco de actividad. Sustancia. Lo acostumbrado. Lo espontáneo. Reino del determinismo y de lo mecánico. El carácter de cada ser en particular. Cfr. R. PANNIKAR (1972): El concepto de naturaleza. Análisis histórico y metafísico de un concepto. $2^{\mathrm{a}}$ ed. Madrid: CSIC.

13 Cfr. T. DE Aquino. Summa Teológica 1-2 q 91 a.2

14 Véase C. CAÑ̃́n (2013): «El Nuevo Ateísmo». Pensamiento, vol. 69, n²61. Serie especial n6, pp. 1057-168, y las referencias allí aportadas. Puede verse también: J. I. GaLPARSORo y A. Cordero (eds.) (2013): o.c. 
de la primera persona; si al segundo, estamos en el ámbito de la tercera persona. Para adentrarse en cada uno de estos ámbitos, van a necesitarse metodologías diferentes. Dilthey propondrá para el segundo la explicación, propia de las ciencias naturales y, en el caso del primero, la comprensión, que será la propia de las por él llamadas «ciencias del espíritu». Ambas responden a dos tipos de experiencias diferentes: la del «cuerpo objetivo» que requiere ser estudiado con conceptos y técnicas de las ciencias experimentales, mientras que la del «cuerpo viviente» incorpora la subjetividad y requiere un tratamiento cualitativo. En los ambientes naturalistas de hoy, una parte del programa consiste en «reducir» el tratamiento de las dimensiones del cuerpo viviente a los del cuerpo objetivo: la mente a cerebro, el lenguaje a comportamiento, el comportamiento a disposiciones, la moral a sentimientos, los sentimientos a emociones,...

Al plantearnos hoy la cuestión de las PIC en relación a la naturaleza humana, nos encontramos con posiciones que reflejan los debates mencionados. Quienes prescinden del «cuerpo viviente» no encuentran necesidad de apelar a nada diferente de lo que los métodos tecnocientíficos requieren para decidir la legitimidad de la intervención: si puede hacerse, hágase. Es la senda emprendida por el postshumanismo. Quienes sin obviar la realidad del "cuerpo viviente», encuentran únicamente nexos entre éste y el "cuerpo objetivo», referidos a la disponibilidad técnocientífica para satisfacer los deseos individuales o las demandas del mercado. Quienes al tratar de conjugar ambas visiones del cuerpo precisan de la consideración de algún tipo de gramática inherente a la naturaleza humana que la constituye en instancia de normatividad para las PIC.

Puede resultar ilustrativo el modo de proceder de la Unión Europea en su SEXTO PROGRAMA MARCO ${ }^{15}$. Los autores del documento consideraban aquel momento, 2005, como un tiempo favorable para que científicos de diversas disciplinas, no sólo las ciencias de la naturaleza, sino las ciencias humanas y la filosofía, trabajaran convergentemente para buscar respuestas a la pregunta: «¿qué significa ser humano?». Es un desafío que, afirman explícitamente, requiere la contribución de todos, incluidos los filósofos. Este desafío exige además novedad en el modo de enfocar este trabajo ${ }^{16}$.

Los humanos somos parte de la naturaleza, fruto de la evolución efectuada a través de la selección natural, y de ahí que la investigación y el análisis científico sea fundamental; sin embargo, los investigadores que firman el informe sostienen, con el propio Darwin, que los humanos no somos como cualquier otro animal. Poseemos una mente capaz de autoconsciencia, somos capaces de producir instrumentos y lenguaje, de hacer matemáticas, de sentir emociones complejas como gratitud, enamoramiento, culpabilidad, remordimiento, perdón, de adorar a Dios (o a dioses), de hacer promesas y de apreciar el arte. Y abordar todo esto les parece a los autores de este informe, que requiere algo más que el método de las ciencias de la naturaleza ${ }^{17}$.

Este extremo ha sido confirmado por el Proyecto Genoma humano que nos ha llevado más allá del determinismo genético mostrando como la contraposición tradicional de

15 http://europa.eu.int/comm/research/rtdinfo/index_en.html

16 Véase el informe publicado en 2005 con el título: «What it means to be human. Origins and Evolution of Human Higher Cognitive Faculties» Report of a NEST High-Level Expert Group NEST —New and Energing Science and Technology_. Este informe comienza diciendo: «The principal recommendation of this report is for the creation of a Human Mind Project to complement and build upon the achievements and discoveries of the Human Genome Project. The aim of the Human Mind Project is to promote interdisciplinary research on what it means to be human» (p.1)

17 Para los autores de este informe, la mente es el corazón de la unicidad de nuestra especie y la esencia de lo que significa ser humano. Cómo definir la mente y cómo dar cuenta de sus operaciones es algo que entra dentro del ámbito de los problemas duros de las ciencias neurológicas. Véase p.e. C. CAÑón (2013): o. c. p.1063. 
naturaleza y crianza o entre genes y entorno está fuera de lugar porque ambos están íntimamente trenzados. Nuestros genes no dictan quiénes somos. Cómo pensamos o cómo nos comportamos, está íntimamente ligado al contexto donde se producen las experiencias de la vida. La mente humana tiene capacidad de ir creando nuevas condiciones para nuestro entorno y éste la va modelando a su vez. De ahí que las ciencias humanas y las ciencias sociales, con la ayuda de la filosofía, estén llamadas a converger, a crear un nuevo paradigma para dar cuenta del ser humano, que supere la dicotomía metodológica actualmente existente.

Coexisten así, en este tiempo búsquedas insertas en estos dos modos básicos de contemplar la realidad humana. Por una parte, quienes sólo toman en consideración el «cuerpo objetivo» desde la perspectiva del naturalismo humeano enriquecido con reflexiones apoyadas en logros indudables de la ciencia natural. Esta aproximación ha llegado, en los escritos de algunos científicos y filósofos, a proclamar militantemente un ateísmo cuyo sustrato fundamental es el evolucionismo y algunos resultados experimentales orientados a naturalizar las dimensiones espirituales humanas ${ }^{18}$. Por otra, el de quienes, como hemos dicho, reconocen en el ser humano dimensiones y capacidades que no son susceptibles de ser tratadas con el método de las ciencias naturales, se aproximan al «cuerpo viviente», además de hacerlo al «cuerpo objetivo» ${ }^{19}$. En este segundo caso, los hilos discursivos que reconocen una gramática en la naturaleza humana coexisten con búsquedas que apuntan al concepto de persona como sustentador de la dimensión ética de aquélla. En este contexto, se están desarrollando multitud de proyectos de investigación, congresos académicos, publicaciones, etc. para tratar la cuestión de la mejora humana ${ }^{20}$. Además de explicar, se requiere comprender, y esto requiere ser elaborado de una manera nueva, con una metodología que integre y supere a ambas.

\subsection{Vo las valoraciones éticas a las que se apela para legitimar la transformación}

Como es de esperar, las referencias éticas de los autores que tratan las cuestiones sobre mejora humana, son consistentes con sus posiciones ontológicas y epistemológicas a las que hemos hecho alusión en los apartados anteriores. En buena parte del ámbito anglosajón, las iniciativas más significativas que se centran en la mejora del individuo humano están elaboradas en la perspectiva de un naturalismo fuerte, ¿por qué no hacerlo «si los científicos Cognitivos pueden pensarlo, la gente Nano puede construirlo, la gente Bio puede implementarlo y la gente IT (tecnologías de la información) puede monopolizarlo y controlarlo? „21.

En las últimas décadas las corrientes de naturalización han abarcado los diversos ámbitos de lo que denominábamos más arriba «el hombre viviente». La reducción de los sentimientos a emociones y los intentos de fundamentar una ética en ellas está siendo objeto de diversas investigaciones ${ }^{22}$. Los científicos y filósofos que militan en lo que conocemos como Nuevo Ateísmo han teorizado acerca de la naturalización de la

18 Véase C. CAÑón (2013): o. c.

19 Véase a este respecto los artículos de Alfredo Marcos y Jesús Conill en este mismo volumen.

20 El proyecto de investigación en el que se desarrolla este trabajo es uno de ellos.

21 Roco\&Bainbridge, 2003, p.13. Citado por N. URsúa (2013): o. c. página 132.

22 El pasado mes de abril se celebró en Asís el Congreso bianual de ESSAT (European Society for Science and Theology) sobre el tema: Do emotions shape the world? La publicación (en prensa) de las ponencias y comunicaciones presentadas será una referencia importante de cómo se están tratando estas cuestiones. 
dimensión espiritual humana y de su libertad ${ }^{23}$. Alguien ha dicho: «si lo conseguimos, estaremos muy cerca de completar la naturalización de la mente humana» ${ }^{24}$ Pero ni siquiera hay acuerdo acerca de qué sea la mente ${ }^{25}$. Así las cosas, sin embargo, el deseo de encontrar el sustrato corporal para actuar sobre las dimensiones del «hombre viviente» es una constante en muchos ámbitos de investigación actuales con el objetivo de llevar a cabo mejoras en el ser humano.

Julian Savulescu plantea una cuestión en esta dirección, cuando busca legitimación moral para la mejora con referencia a la licitud de la terapia. Su argumento es el siguiente: hay genes patológicos que están en la base de algunas enfermedades y conductas asociales importantes. Intervenir en ellos podría comprenderse como terapia. Pero hay también genes que están relacionados con alguno de los aspectos integrantes de la sabiduría, en su acepción socrática. No son genes patógenos, pero su mejora podría lograr mejores resultados en alguna de las componentes de la sabiduría del individuo, y por tanto en lograr una mejora en su vida buena ${ }^{26}$. Y en la medida en que la mejora en alguna de estas capacidades pueda ser técnicamente viable, ¿podría considerarse legítima éticamente? Su posición utilitarista le lleva a concluir afirmativamente ya que mejorar la sabiduría es útil para el individuo y para la sociedad.

Y yendo por la misma senda, da un paso más en el marco de una ética naturalizada. Se pregunta por las posibilidades que tenemos de obtener mejoras morales interviniendo en el núcleo de nuestras disposiciones morales, una vez localizado en el cuerpo humano. Su respuesta es que sí, porque «hay razones para pensar que compartimos este núcleo de disposiciones morales que hemos identificado con algunos animales no humanos» ${ }^{27}$.

Otro autor, De Grazia, define la mejora humana como «cualquier intervención deliberada cuyo objetivo sea mejorar una capacidad existente, seleccionar para una capacidad deseada, o crear una nueva capacidad en un ser humano ${ }^{28}$. Quizás, esta definición de De Grazia pueda evocar también la invitación de Ortega y Gasset a que cada hombre invente la novela de su propia vida pues la técnica le ayudará a realizarla. Lo que a Ortega su tiempo no le invitó a pensar es en la posibilidad no sólo de mejorar una capacidad existente, o seleccionar para una capacidad deseada, sino incluso crear una nueva capacidad en el ser humano. De Grazia no sólo parece moverse en el horizonte de incidir en una naturaleza naturalizada, sino que apunta al paraguas abierto de una utopía con elementos de transhumanismo ${ }^{29}$.

Para todos estos autores ${ }^{30}$ se diría que hacer lo posible por lograr las mejoras en los grados mencionados, no sólo es positivo, sino que sería inmoral no perseguirla. La

23 Cfr. C. CAÑóN (2013): o. c.

24 P. Quintanilla (2013): «Naturalism and the mind. Las cuestiones finales» en J. I. Galparsoro y A. Cordero (eds.) (2013): o.c. p. 42.

${ }_{25}$ Cfr. I. Morgado (2012): Cómo percibimos el mundo. Una exploración de la mente y los sentidos. Barcelona: Ariel. Véase en particular el Epílogo: los límites del cerebro y la mente humana pp. 207-215. Y véase también la Nota 15 de este texto.

26 Recordemos que Platón nos cuenta en el Filebo cómo Sócrates había llegado a la conclusión de que una vida humana buena conjuga siempre sabiduría y placer, la primera incluye la inteligencia, el pensamiento, la capacidad lógica, el conocimiento y la memoria.

27 J. Savulescu (2012): ¿Decisiones peligrosas? Una Bioética desafiante. Madrid: Tecnos, p.238.

28 Véase L. Feito (2013): «El debate ético sobre la mejora humana», Diálogo filosófico, № 86, pp. 267-290.

29 Una excelente reflexión sobre la superación del naturalismo en Ortega puede encontrarse en: J. Conill-SANCHo (2012): «La superación del naturalismo en Ortega y Gasset», Isegoría, n46, pp. 167-192.

30 Julian Huxley (creador del término en 1957), Nick Bostrom, David Pearce, Julián Savulescu. Véase: L. Feito (2011): «La búsqueda de la perfección: ¿realización de lo humano o pacto con el diablo?» 
razón humana es capaz de tomar decisiones sabias y es una obligación moral desarrollar nuestra capacidad hasta sus límites. La naturaleza humana es algo dinámico y en progreso, que podemos aprender a remodelar de modos deseables. El compromiso con una vida humana en evolución implica la defensa de la ciencia y la tecnología, que hacen viable la programación de esas mejoras, y también la promoción de estilos de vida, hábitos y modelos sociales que se introduzcan en esta corriente para posibilitar el mayor bien para el mayor número, de modo que pueda lograrse la utopía de lograr ser posthumanos. Consistentes con el liberalismo que habitan, dejan a la libertad individual y a la capacidad racional la decisión de en qué pueda consistir la mejora humana ${ }^{31}$.

A este tipo de posiciones se oponen por razones diversas un amplio sector de autores. Algunos, porque siguen sosteniendo que la naturaleza tiene un orden intrínseco que es inviolable e inalterable. Otros, porque aun considerando que no hay maldad intrínseca en la mejora planteada tan ampliamente, sostienen que sus posibles consecuencias pueden ser nefastas para el individuo y la sociedad. En algunos casos, el rechazo incluye tanto la apelación a la naturaleza humana, como las consecuencias que se seguirían. Sería el caso puesto de manifiesto en la polémica sostenida por Habermas y Sloterdijk al proponer éste la modificación genética como forma de realizar un proyecto humanizador $^{32}$. En su obra El futuro de la naturaleza humana, Jürgen Habermas utiliza la expresión «fijar agujas» (die Weichen stellen) para significar, no solo un cambio de rumbo, sino sobre todo la puesta en marcha de algo en una dirección predefinida que queda establecida precisamente con ese acto $^{33}$. La usa en particular en el contexto del diagnóstico preimplantatorio, para ilustrar el punto clave de su crítica. Este tipo de mejora supone una ruptura de los ámbitos de lo subjetivo y lo objetivo, de «lo crecido» y «lo hecho», una forma de instrumentalización y una falta de respeto a la dinámica propia de una naturaleza que se autorregula, y que ha de servir de guía a las intervenciones humanas so pena de incurrir en grandes males.

Con argumentaciones propias, muy incisivas, el profesor de Harvard, Michael Sandel, situado en la tradición aristotélica, denuncia que el deseo de ir más allá de lo que está escrito en nuestra naturaleza conlleva un afán de dominio extremadamente peligroso para nuestras sociedades. Argumenta que la búsqueda de la perfección es imperfecta y muestra con casos finamente trabajados, que la revolución genética acabará transformando el modo en que se discute sobre cuestiones éticas, pues evidenciará la necesidad de abordar cuestiones que la modernidad ha marginado y a reintroducir las cuestiones de orden espiritual en el centro del debate político. Rechaza cualquier tipo de intervención biotecnológica orientada a mejorar las capacidades de la naturaleza humana individual. Se sigue que hemos de restringir nuestro uso de las biotecnologías

en J. San Martín, T. Domingo Moratalla (eds.) (2011): Perspectivas sobre la vida humana: cuerpo, mente, género y persona. Madrid: Biblioteca Nueva.

31 Puede verse la Declaración Transhumanista de la World Transhumanist Association: http://humanityplus.org/philosophy/transhumanist-declaration/

32 Véase P. SloterdiJK (2000): Normas para el parque humano. Madrid: Siruela.

33 Son pertinentes las matizaciones hechas por José Luis Caballero en las nota 2 de su artículo: «Metáfora técnica del cambio de agujas y acción comunicativa» a la traducción española de la obra: J. Habermas (2005): Die Zukunft der menschlichen Natur. Auf dem Weg zu einer liberalen Eugenik?. Frankfurt: Suhrkamp; J. HABERMAS (2009, reimpresión de 2010): El futuro de la naturaleza humana. ¿Hacia una eugenesia liberal? Barcelona: Paidós. Esta versión traduce la expresión «die Weichen falsch stellen» (p.45) (fijar las agujas de manera equivocada), que aplica Habermas a los argumentos acerca del debate sobre el aborto, como: "van mal encaminados»(p. 37 de la edición española). La traducción no es incorrecta, pero anula por completo la referencia al mecanismo. Son relevantes también los comentarios de L. FEITo (2013): o. c. pp. 286-287. 
al ámbito terapéutico y a la restauración de las capacidades normales y naturales de los seres humanos ${ }^{34}$.

Una posición más radical, que identifica lo natural como necesariamente bueno, con la consiguiente oposición a cualquier intervención tecnológica orientada a implementar supuestas mejoras, es la de algunos que ven en cualquier alteración en la naturaleza humana individual, un atentado contra la dignidad y una deshumanización por la pérdida de sentido que comporta. Entre los autores que sostienen estos puntos de vista estarían Leon Kass, que apela a la "sabiduría de la repugnancia». Según este autor, existe una sabiduría en nuestro sentimiento de repugnancia que subyace a todo argumento racional. En casos cruciales, "la repugnancia es la expresión de una profunda sabiduría». Así «la repugnancia se rebela contra los excesos de la voluntad humana, nos alerta a no trasgredir aquello que por profundo es indecible» ${ }^{35}$. También ha tenido eco la posición crítica de Jeremy Rifkin con el argumento conocido como «slippery slope» (argumento de la pendiente resbaladiza), que aunque desde el punto de vista lógico no es conclusivo, sin embargo es utilizado como un modo de alertar respecto de las consecuencias que pueden seguirse: una vez iniciado el proceso, ¿dónde detenerse? ${ }^{36}$

Este recorrido nunca exhaustivo ${ }^{37}$, pero suficiente para el objetivo de este artículo, evidencia la variedad de posturas éticas respecto de la cuestión de la mejora humana. A la vez, muestra cómo más allá de las corrientes de escuela que subyacen a las argumentaciones éticas, está siempre, en el corazón de los debates, la cuestión de la naturaleza humana.

\section{REFLEXiONES FINALES}

En este análisis he prescindido de la división entre terapia y mejora, englobando ambas bajo el concepto de "práctica de intervención en el cuerpo humano» (PIC), que se desarrollan teniendo en cuenta cinco factores $<\mathrm{M}, \mathrm{CT}, \mathrm{A}, \mathrm{N}, \mathrm{V}\rangle$, presentados en la segunda parte. En las conclusiones que siguen emergen nuevos modos de establecer la relación entre estos dos conceptos. En el análisis hemos evidenciado:

1) Que el avance del conocimiento y de las técnicas disponibles lejos de facilitar el trazado de las líneas morales descritas en la primera parte, han hecho más compleja su búsqueda e incluso su viabilidad.

Los dos tipos de argumentos ofrecidos por el Dr. Anderson, que mencioné al principio como «el conocimiento no suficiente» $\mathrm{y}$ "la actual precariedad del criterio moral común» se han transformado en estas últimas décadas hasta arrojar una complejidad como la que hemos tratado de mostrar, inimaginable entonces. Así, las conclusiones 1 y 2 que apuntábamos en «el ayer» se insertan ahora en el debate en una antropología situada en el marco de una "evolución calculada» con los reclamos del transhumanismo. Una perspectiva que niega la necesidad de trazar una línea moral, porque el concepto de mejora queda subsumido en el proceso de evolución de la especie.

34 Véase su libro: M. SANDEL (2007): Contra la perfección. Barcelona: Marbot.

35 L. Kass y J. Q. Wilson (1998): The ethics of human cloning. American Enterprise Institute. pp. $18-19$

36 Puede verse J. Rifkin (1983): Algeny. Penguin Books, p. 232, y también el publicado al final de los años 90: The Biotech Century: Harnessing the Gene and Remaking the World. New York: J P Tarcher, 1998.

37 Un trabajo hecho con exhaustividad sobre este punto es el artículo ya citado de Lydia Feito. 
2) Las consecuencias de la crisis de la metafísica y la prevalencia de concepciones naturalizadas del ser humano hacen obsoleta para un amplio sector, la diferencia entre terapia y mejora. La dimensión prescriptiva de la terapia, emana de una naturaleza humana normativa. Al negarle éste carácter desaparecen los criterios para decidir qué es bueno hacer y qué no. No se sabe en realidad qué es mejor. Es por eso que las propuestas que prescinden de toda dimensión normativa de la naturaleza humana no se pueden llamar estrictamente de mejora, sino de cambio: son genéricamente PIC, pues proponen cambiar al ser humano, pero no aportan criterios para saber si este cambio es a mejor, a peor, o indiferente.

Además, vale aquí el argumento central de Jonas, según el cual «la posibilidad de valor es ya un valor». De ahí se sigue que la indiferencia axiológica es, en realidad, un disvalor o una pérdida de valor. Dicho de otro modo — con Soloviev— más allá del bien y del mal... está el mal. Por lo que, lejos de desaparecer el concepto de terapia para dejar todo el campo a la mejora, las PIC parecen apuntar bien a la terapia, bien a cambios que comportan una pérdida de valor y conducen por ello a una indiferencia axiológica. Podría decirse que son propuestas de «cambio a peor» ${ }^{38}$.

3) La conclusión 3 de la parte primera está diversificada en un debate en el que el papel fundamental lo juegan diversas propuestas éticas en litigio. Cada una reclama para sí la no arbitrariedad, pero muestran conclusiones claramente diferentes. En varias de ellas, como hemos señalado, la mejora no se caracteriza por su relación con la terapia, sino con los deseos individuales y las posibilidades técnicas disponibles. Es decir, si en el planteamiento del Dr. Anderson el carácter prescriptivo del concepto de terapia era la instancia legitimadora de la intervención técnica, ahora esta instancia se amplía bien a la consideración subjetiva de lo que "considero bueno para mí», bien al imperativo de la demanda del mercado.

4) Las diferencias en el criterio moral hay que situarlas, para encauzar un diálogo fecundo, en un nivel ontológico. El concepto de naturaleza humana como instancia normativa no ha encontrado aún sustituto y su ausencia dejaría un vacío que, en caso de afirmarse, haría urgente reconocer y apuntar hacia otro concepto $^{39}$, que pueda aglutinar y dejar a salvo la dignidad de cada ser humano. Es esta noción la que precisa ser recreada, la que necesita un debate que no se ahorre ninguno de los elementos que hemos introducido en la caracterización de la PIC: <M, CT, A, N, V>.

5) La búsqueda de esa instancia normativa común, precisa de un trabajo interdisciplinar, o transdisciplinar, que ponga en relación las cinco componentes con que caracterizábamos las PIC. Esta resulta ser la tarea central que emerge en las búsquedas en el presente. Y en esta tarea, no sólo se precisa la concurrencia de saberes, porque al estar en juego la afirmación común de qué sea el ser humano, emerge como elemento fundamental el modo de hacerlos presentes: la deliberación como método. Lo expresa bien Gadamer cuando dice:

«No hay un saber que pueda pretender una validez general. Por eso se precisa deliberación, que implica una coincidencia muy diferente a la de lo universalmente válido.

38 Agradezco a Alfredo Marcos el contraste que me ha ofrecido sobre este punto.

39 Véase el artículo de Jesús Conill-Sancho en este mismo volumen. 
La deliberación hacer hablar a otro y enfrentarse a él. Por eso no puede objetivarse hasta el final al modo de la ciencia. (...) Lo que hay al final de esa deliberación no es sola la realización de una obra o el logro de un estado anhelado, sino una solidaridad que nos une a todos» ${ }^{40}$.

Universidad Pontificia Comillas, Madrid

CAMino Cañón Loyes

cloyes@chs.upcomillas.es

[Artículo aprobado para publicación en diciembre de 2014].

40 H. G. Gadamer (1992): Verdad y Método II. Salamanca: Sígueme, p. 165. Agradezco a Antonio Sánchez Orantos la sugerencia de esta cita. 